\title{
Targeting glutathione-S transferase enzymes in musculoskeletal sarcomas: A promising therapeutic strategy
}

\author{
Michela Pasello $^{\mathrm{a}}$, Maria Cristina Manara ${ }^{\mathrm{a}}$, Francesca Michelaccia ${ }^{\mathrm{a}}$, Marilù Fanelli ${ }^{\mathrm{a}}$, Claudia Maria \\ Hattinger ${ }^{\mathrm{a}}$, Giordano Nicoletti ${ }^{\mathrm{a}}$, Lorena Landuzzi ${ }^{\mathrm{a}}$, Pier Luigi Lollini ${ }^{\mathrm{b}}$, Annamaria Caccuri ${ }^{\mathrm{c}}$, \\ Piero Piccia ${ }^{\mathrm{a}}$,Katia Scotlandi ${ }^{\mathrm{a}}$ and Massimo Serra ${ }^{\mathrm{a}, *}$ \\ ${ }^{a}$ Rizzoli Orthopaedic Institute, Laboratory of Experimental Oncology, Bologna, Italy \\ ${ }^{\mathrm{b}}$ Department of Hematology and Oncological Sciences, University of Bologna, Bologna, Italy \\ ${ }^{\mathrm{c}}$ Department of Chemical Sciences and Technologies, University of "Tor Vergata", Rome, Italy
}

\begin{abstract}
Recent studies have indicated that targeting glutathione-S-transferase (GST) isoenzymes may be a promising novel strategy to improve the efficacy of conventional chemotherapy in the three most common musculoskeletal tumours: osteosarcoma, Ewing's sarcoma, and rhabdomyosarcoma. By using a panel of 15 drug-sensitive and drug-resistant human osteosarcoma, Ewing's sarcoma, and rhabdomyosarcoma cell lines, the efficay of the GST-targeting agent 6-(7-nitro-2,1,3-benzoxadiazol-4ylthio)hexanol (NBDHEX) has been assessed and related to GST isoenzymes expression (namely GSTP1, GSTA1, GSTM1, and MGST). NBDHEX showed a relevant in vitro activity on all cell lines, including the drug-resistant ones and those with higher GSTs levels. The in vitro activity of NBDHEX was mostly related to cytostatic effects, with a less evident apoptotic induction. NBDHEX positively interacted with doxorubicin, vincristine, cisplatin but showed antagonistic effects with methotrexate. In vivo studies confirmed the cytostatic efficay of NBDHEX and its positive interaction with vincristine in Ewing's sarcoma cells, and also indicated a positive effect against the metastatisation of osteosarcoma cells. The whole body of evidence found in this study indicated that targeting GSTs in osteosarcoma, Ewing's sarcoma and rhabdomyosarcoma may be an interesting new therapeutic option, which can be considered for patients who are scarcely responsive to conventional regimens.
\end{abstract}

Keywords: Musculoskeletal sarcomas, glutathione metabolism, novel antitumour agents, target therapies

\section{Introduction}

Osteosarcoma and Ewing's sarcoma are the two most frequent bone tumours. Although these two neoplasms show several differences with respect to their origin and biological and molecular features, they share a similar clinical history. Both are very aggres-

*Corresponding author: Dr. Massimo Serra, Laboratorio di Oncologia Sperimentale, Istituto Ortopedico Rizzoli, Via di Barbiano 1/10, 40136 Bologna, Italy. Tel.: +39 051636 6762; Fax: +39 051636 6761; E-mail: massimo.serra@ior.it. sive tumours with a marked tendency to recur and metastasize to the lungs and/or the skeleton [1, 4, 12]. The introduction of chemotherapy has significantly improved the prognosis of osteosarcoma and Ewing's sarcoma non-metastatic patients, shifting the 5 -year survival rate to around $60-65 \%$. However, clinical studies have clearly indicated that this survival rate has reached a plateau, which can not be further improved by conventional treatment regimens $[4,12]$.

Rhabdomyosarcoma is the most common soft tissue sarcoma in children and adolescents, accounting for approximately $5 \%$ of all pediatric cancers and $50 \%$ of soft tissue sarcomas. Rhabdomyosarcoma is 
a highly malignant mesenchymal tumour thought to originate from immature striated muscle. Thanks to the combined use of intensive multimodal therapy (including surgery, radiotherapy, and chemotherapy) the cure rate for patients with rhabdomyosarcoma reaches $70 \%$ for patients with nonmetastatic disease. However, like in osteosarcoma and Ewing's sarcoma, multimodal therapy can be associated with acute toxicities and long-term adverse effects, such as growth and developmental defects, which severily affect quality of life of young rhabdomyosarcoma survivors [16].

One major problem encountered in the management of these musculoskeletal tumours is the development of treatment unresponsiveness, which eventually leads to relapse and to a poor clinical outcome $[4,12,16]$. Successful treatment of therapy-resistant or scarcely responsive patients requires new strategies and novel drugs, which target molecules or pathways that play relevant biologic roles in these sarcomas.

Recent studies have indicated that targeting glutathione-S-transferase (GST) isoenzymes, which are involved in xenobiotics detoxification and in the regulation of the apoptotic signal transduction, may be a promising novel strategy to improve the efficacy of conventional chemotherapeutic drugs in osteosarcoma [8], Ewing's sarcoma [12], and rhabdomyosarcoma [13].

In osteosarcoma, we have demonstrated that overexpression at diagnosis of the glutathione-S-transferase P1 (GSTP1) isoenzyme is associated with a higher relapse rate and a worse prognosis, as a consequence of a reduced responsiveness to conventional treatments [8]. In addition, in our osteosarcoma experimental models, the increase of both intracellular levels and enzymatic activity of GSTP1 resulted to be associated with the degree of resistance against cisplatin and, at a lower extent, to doxorubicin [8].

In Ewing's sarcoma, alteration of the glutathione metabolic pathway emerged as one of the most significant prognostic markers and the expression of the membrane-bound microsomal glutathione Stransferase (MGST) was found to be the most strictly prognosis-related isoenzyme of the GST family [12].

In human rhabdomyosarcoma cells, GST genes have been indicated to be involved in the acquisition of a multidrug resistant phenotype, suggesting that GSTs (in particular the GSTPi isoenzymes) may play a role for clinical chemotherapy resistance [13].

Targeting GST isoenzymes with the new agent 6(7-nitro-2,1,3-benzoxadiazol-4-ylthio)hexanol (NBD-
HEX) $[3,9,18]$ has proved to be a promising strategy for improving the efficacy of conventional chemotherapeutic drugs on osteosarcoma and Ewing's sarcoma cell lines [8, 12], whereas no data are available on rhabdomyosarcoma. However, additional information about the in vitro and in vivo efficacy of NBDHEX and the evaluation of its interaction with the drugs which are most commonly used in osteosarcoma, Ewing's sarcoma and rhabdomyosarcoma chemotherapy are needed, in order to better define the potential clinical value of this new agent.

In this study, in order to define whether NBDHEX may be considered for drawing new multidrug chemioterapeutic regimes for unresponsive patients, its activity was tested against osteosarcoma, Ewing's sarcoma and rhabdomyosarcoma cell lines and related to the GST isoenzymes intracellular contents. The influence of NBDHEX on apoptosis, cell cycle distribution and its combined effects with doxorubicin, methotrexate or vincristine were also analysed, together with its in vivo efficacy and collateral toxicity.

\section{Materials and methods}

\subsection{Drugs}

Cisplatin (CDDP), doxorubicin (DX), methotrexate (MTX) and vincristine (VCR) were purchased from Sigma-Aldrich (Milan, Italy). NBDHEX was synthetised as reported by Ricci et al. [9]. Stock solutions of CDDP $(500 \mu \mathrm{g} / \mathrm{mL})$, DX $(2 \mathrm{mg} / \mathrm{mL})$, MTX $(25 \mathrm{mg} / \mathrm{mL})$ and VCR $(1 \mathrm{mg} / \mathrm{mL})$ were stored at $4^{\circ} \mathrm{C}$. NBDHEX was dissolved in DMSO at a $100 \mathrm{mM}$ concentration and stock solution aliquots were stored in darkness at room temperature. Immediately before use, the integrity of NBDHEX molecule was verified by spectroscopy. After dilution of NBDHEX stock solutions to the appropriate concentration required for the in vitro experiments, the final DMSO concentration did never exceed $0.01 \%$, a dosage at which it had no cytotoxic effect on our cell lines. For all drugs, working concentrations were prepared by diluting stock solutions in culture medium immediately before use.

\subsection{Cell lines}

The human osteosarcoma cell lines U-2OS and Saos-2 and the human Ewing's sarcoma cell lines 
TC-71, 6647 and SK-ES-1 were obtained from the American Type Culture Collection (ATCC, Rockville, MD).

The alveolar rhabdomyosarcoma cell lines SJRH30 and SJ-RH4 were provided, respectively, by Dr. A. Rosolen (University of Padua, Padua, Italy) and Dr. D. N. Shapiro (St. Jude Children's Hospital, Memphis, TN). The alveolar rhabdomyosarcoma cell line RMZ-RC2 (named RC2) was established at the Cancer Research Section, Department of Experimental Pathology, University of Bologna, Bologna, Italy [6]. The RD/18 cell line is a clone, obtained at the Cancer Research Section, University of Bologna (Italy) of the commercially available human embryonal rhabdomyosarcoma RD cell line (Flow Laboratories, Rockville, MD). The DX-, MTX-, and CDDP-resistant variants of human osteosarcoma cell lines were established by exposing the sensitive U-2OS and Saos-2 parental cell lines to stepwise increasing concentration of each drug $[8,14,15]$.

All cell lines were cultured in Iscove's modified Dulbecco's medium (IMDM), supplemented with penicillin $(100 \mathrm{U} / \mathrm{mL}) /$ streptomycin $(100 \mu \mathrm{g} / \mathrm{mL})$ (Invitrogen Ltd, Paisley, UK) and 10\% heat-inactivated fetal bovine serum (FBS; Biowhittaker Europe, CambrexVerviers, Belgium). Each drug resistant variant was continuously cultured in presence of the drug concentration used for its selection. All cell lines were maintained at $37^{\circ} \mathrm{C}$ in a humidified $5 \% \mathrm{CO}_{2}$ atmosphere.

\subsection{Assessment of GST isoenzymes}

Analyses of GSTs focused on the microsomal isoenzyme (MGST) and on the isoenzymes of the $\pi$-class GST (GSTP), $\mu$-class GST (GSTM), and $\alpha$-class (GSTA).

Assessment of GST genes expression in cell lines was performed by real-time PCR with predesigned TaqMan probes and primers set for each gene, as previously described $[8,12]$. Samples were analysed using an ABI Prism 7900 Sequence Detection System (Applied Biosystem, Foster City, CA), according to manufacturer's instructions. Expression level of target gene was normalised to that of glyceraldehyde 3-phosphate dehydrogenase (GAPDH), and the relative quantification analysis was performed on the basis of the $\Delta \Delta \mathrm{CT}$ method. For comparative analysis of gene expression levels, pooled cDNA from human normal muscle cells, human normal osteoblasts and human bone marrow CD34-positive cells were used as calibrators.

MGST gene expression level was also analysed in the previously described series of 34 tumour biopsies obtained from primary, non-metastatic, highgrade osteosarcoma patients treated with conventional neoadjuvant chemotherapy protocols based on the administration of DX, MTX, CDDP and ifosfamide [8]. Before RNA extraction, all clinical samples were histologically examined for tissue quality and representativity. The expression level of the MGST gene was normalised to that of GAPDH and the relative quantification analysis was based on the $\Delta \Delta \mathrm{Ct}$ method. A pooled cDNA from human normal osteoblasts was used as calibrator and clinical cases were stratified into high- or low-expressing MGST by using the median $M G S T$ gene expression value as cut-off.

Intracellular levels of $\pi$-class GST (GSTP), $\mu$-class GST (GSTM), and $\alpha$-class GST (GSTA) proteins were estimated by western blot with the following primary antibodies: NCL-GSTPpi (specific for $\pi$-class GST; Novocastra Lab, Newcastle, UK), anti-GSTM1 (specific for $\mu$-class GST; Novus Biologicals, Littleton, CO), anti-GSTA1 (specific for $\alpha$-class GST; Novus Biologicals). All primary antibodies were diluted $1: 500$ in TTBS/1\% (w/v) non-fat milk. To verify the protein loading of each sample, after stripping of the primary antibody, the same membranes were immunostained with an anti-beta-actin monoclonal antibody (Chemicon International, Temecula, CA). For each band, the amount of GST protein was determined by densitometric analysis and normalised to that of beta-actin by using as image analyser the GelLogic 2200 Imaging system (KODAK, Rochester, NY).

\subsection{NBDHEX in vitro efficacy}

NBDHEX sensitivity of each cell line was calculated from the drug dose-response curves obtained by using a standard 3-(4,5-dimethylthiazol-2-yl)2,5-dephenyltetrazolium bromide (MTT) assay kit (Roche Diagnostics GmbH, Mannheim, Germany) and expressed as IC50 (drug concentration resulting in 50\% inhibition of cell growth after 72 hours of in vitro treatment for Ewing's sarcoma and rhabdomyosarcoma, or 96 hours of in vitro treatment for osteosarcoma cell lines). 


\subsection{Cell cycle analysis}

Assessment of the NBDHEX effects on cell cycle was performed by seeding 20,000 cells $/ \mathrm{cm}^{2}$ in IMDM $10 \%$ FBS. After 24 hours, medium was changed with IMDM $10 \%$ FBS without (control) or with the NBDHEX IC50 or IC75 concentration of each cell line. NBDHEX treatment was performed for 72 hours for osteosarcoma and for 48 hours for Ewing's sarcoma and rhabdomyosarcoma cell lines. After drug exposure, cells were incubated with $10 \mu \mathrm{M}$ bromodeoxyuridine (Sigma-Aldrich) for 1 hour in a humidified $5 \% \mathrm{CO}_{2}$ atmosphere at $37^{\circ} \mathrm{C}$, harvested, and fixed in $70 \%$ ethanol for 30 minutes. After DNA denaturation with $2 \mathrm{~N} \mathrm{HCl}$, cells were processed for indirect immunofluorescence staining with the B44 anti-bromodeoxyuridine monoclonal antibody (Becton Dickinson, San Jose, CA) diluted $1: 4$, followed by an anti-mouse FITC antibody (Sigma-Aldrich) diluted $1: 20$. For the simultaneous determination of DNA content, cell suspensions were stained with $20 \mu \mathrm{g} / \mathrm{mL}$ propidium iodide (Sigma-Aldrich). All samples were analysed by flow cytometry (FACSCalibur, Becton Dickinson).

\subsection{Apoptosis assay}

Assessment of the NBDHEX effects on apoptosis was performed by seeding 20,000 cells $/ \mathrm{cm}^{2}$ in IMDM $10 \%$ FBS. After 24 hours, medium was changed with IMDM $10 \%$ FBS without (control) or with the NBDHEX IC50 or IC75 concentration of each cell line. The induction of apoptosis was assessed after 48 hours of drug treatment with the annexin-V-FITC assay with the MBL MEBCYTO Apoptosis kit (Medical and Biological Laboratories, Naka-ku Nagoya, Japan). DNA staining with $20 \mu \mathrm{g} / \mathrm{mL}$ propidium iodide (SigmaAldrich) was used to discriminate necrotic cells (which showed simultaneous annexin-V-FITC and propidium iodide staining) from apoptotic cells (which showed only annexin-V-FITC staining).

\subsection{Evaluation of drug-drug interactions}

To evaluate the in vitro interactions between NBDHEX and conventional chemotherapeutic drugs, human osteosarcoma cell lines were incubated with different regimens of two-drugs combinations (association or sequential exposure of NBDHEX with each conventional drug), as previously described [8]. The same experimental schedule was used for Ewing's sarcoma and rhabdomyosarcoma cell lines, with the only difference that the drug interaction effects were evaluated after 72- instead of 96 hours of treatment. To define the type of interaction between NBDHEX and each conventional drug (in terms of synergism, antagonism or additivity), the combination index (CI) of each two-drugs combination was calculated with the equation of Chou-Talalay [2], by using the CalcuSyn software (Biosoft, Stapleford, UK). By following the range of $\mathrm{CI}$ values reported in the CalcuSyn software manual and recommended by Chou and colleagues [2], we classified the drug-drug interaction as synergistic when CI was lower than 0.90 , as additive when $0.90 \leq \mathrm{CI} \leq 1.10$, or as antagonistic when CI was higher than 1.10 .

\subsection{In vivo treatments with NBDHEX}

Athymic Crl:CD-1-Foxn $1^{n u / n u}$ mice (referred to as nude mice) were purchased from Charles River Italy (Lecco, Italy) and kept under sterile conditions. Experiments were authorized by the institutional review board of the University of Bologna and done according to Italian and European guidelines. To evaluate local tumour growth, $5 \times 10^{6}$ TC-71 Ewing's sarcoma cells were injected subcutaneously (s.c.) and tumour growth was assessed two times weekly by measuring tumour volume, calculated as $\pi[\sqrt{(a \cdot b)}]^{3} / 6$, where a maximal tumour diameter and $b=$ tumour diameter perpendicular to $a$. For ethical reasons, tumour-positive mice were sacrificed when tumour reached the volume of $4 \mathrm{~mL}$. Tumour-negative mice were sacrificed three months after cell inoculation by $\mathrm{CO}_{2}$ inhalation. Each day of treatment, NBDHEX stock solution ( $40 \mathrm{mg} / \mathrm{mL}$ ) was diluted with $0.5 \%$ Methyl cellulose (Sigma-Aldrich) to obtain a final concentration of $4 \mathrm{mg} / \mathrm{mL}$. A total dose of $40 \mathrm{mg} / \mathrm{kg}$ NBDHEX was given per os daily, five times per week, starting from day +6 after the s.c. cell injection. One group of mice received VCR intra-peritoneoum ( $1 \mathrm{mg} / \mathrm{kg} / \mathrm{die})$ on the day 6 and 7 . Another group of mice received both NBDHEX and two treatments with VCR following the time schedule mentioned above.

To evaluate NBDHEX activity on mestastatization, nude female mice were itravenously (i.v.) pretreated with anti-asialo GM1 antiserum (Wako, Dusseldorf, Germany), to deplete NK activity [4, 7] $24 \mathrm{hr}$ prior 
to the i.v. injection of $2 \times 10^{6}$ tumour cells of the U$2 \mathrm{OS}$ osteosarcoma cell line. A dose of $40 \mathrm{mg} / \mathrm{kg}$ of NBDHEX was given per os daily, five times per week starting from day +1 after the i.v. cell injection. Mice were sacrificed three months after cell inoculation by $\mathrm{CO}_{2}$ inhalation and necropsied. Lungs were stained with black India ink to outline metastases and fixed in Fekete's solution. Lung and extra-lung metastases were counted using a dissection microscope.

\subsection{Statistics}

Differences among means were analysed with the Student's $t$ test. Kaplan-Meier and log-rank methods were used to draw and evaluate the significance of survival curves. Two-tailed Fisher's exact test was used to evaluate the statistical association between two variables.

\section{Results}

\subsection{GSTs gene and protein expression}

The analysis of GST genes expression on cell lines focused on GSTP1, GSTM1, GSTA1 and MGST (Fig. 1A-D). At gene level, all isoenzymes proved to be variably expressed among the different cell lines, with the only exception of GSTAl that was invariably expressed at very low levels excepting for Saos-2/CDDP6 $\mu$ g cell line (Fig. 1B). No significant difference was found concerning the expression level of each isoenzyme among the groups of osteosarcoma, Ewing's sarcoma and rhabdomyosarcoma cell lines ( $t$ Student test). All isoenzymes proved to be variably expressed also among the different pools of human normal cells, with the exception of GSTM1 which was almost absent in human normal muscle cells (Fig. 1C).
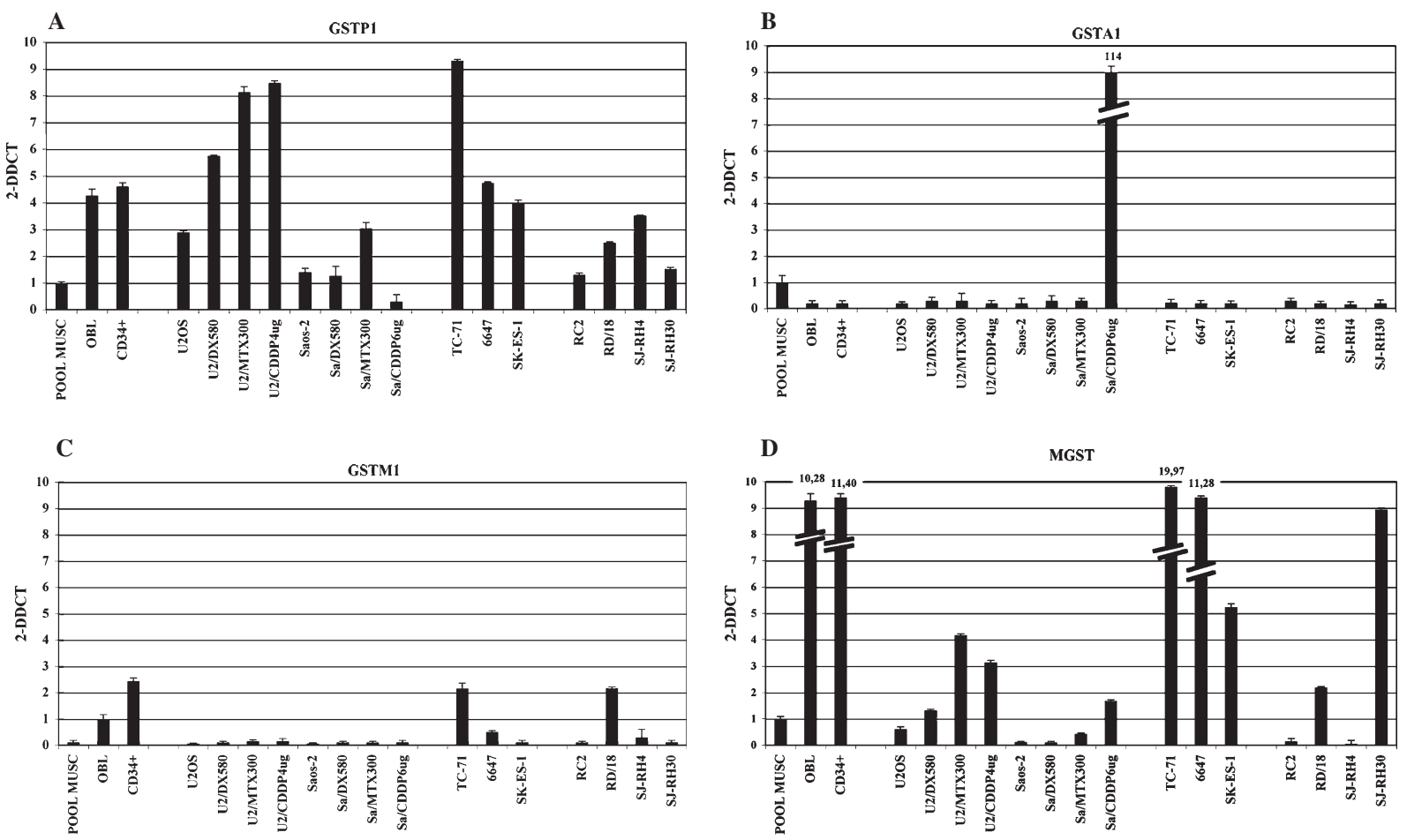

Fig. 1. Relative gene expression level of glutathione-S transferase (GST) isoenzymes in the panel of human osteosarcoma, Ewing's sarcoma and rhabdomyosarcoma cell lines. The gene expression level of GSTP1, GSTA1 and MGST isoenzymes was related to that of human normal muscle cells, whereas human normal osteoblasts were used as calibrator for GSTM1 gene. Graphs show data of one representative experiment. Legend: POOL MUSC, cDNA pool from normal human muscle cells; OBL, cDNA pool from normal human osteoblasts; CD34 ${ }^{+}$, cDNA pool from human bone marrow CD34-positive cells. 
In osteosarcoma cell lines, the gene expression level of these isoenzymes was assessed on the U$2 \mathrm{OS}$ and Saos-2 parental cell lines and on their drug resistant variants U-2OS/DX580, Saos-2/DX580, U2OS/MTX300, Saos-2/MTX300, U-2OS/CDDP4 $\mu \mathrm{g}$, and Saos-2/CDDP6 $\mu \mathrm{g}$. The expression of GSTP1, GSTM1 and MGST isoenzymes in the U-2OS and Saos-2 parental cell lines was invariably lower than that of normal human osteoblasts, which have to be considered as the appropriate reference normal cells. No difference was found concerning GSTA1 expression in U-2OS and Saos-2 cell lines compared to normal osteoblasts.

The comparison between drug resistant variants and their parental cell lines showed a general trend toward an increase of one or more GST isoenzymes in association with the acquisition of drug unresponsiveness, which was more evident in the U-2OS series. As shown in Table 1, GSTP1 gene expression was increased in all U-2OS drug resistant variants and in the Saos2/MTX300 cell line, in agreement with previously reported data [8]. Expression of GSTA1 and GSTM1 genes did not show any increase in osteosarcoma drug resistant variants, with the only exception of Saos2/CDDP6 $\mu \mathrm{g}$ which showed a signifcant enhancement of GSTA1 expression (Table 1). Western blot analyses showed results in agreement with those obtained at gene expression level. GST $\pi$ protein expression was increased in all U-2OS drug resistant variants and in the Saos-2/MTX300 cell line, with fold-increases very similar to those obtained from gene expression

\section{Table 1}

Glutathione-S transferase (GST) isoenzymes expression changes in human osteosarcoma drug resistant variants. Gene expression level, assessed with real-time PCR, was calibrated to normal human osteoblasts

\begin{tabular}{llccc}
\hline & \multicolumn{4}{c}{$\begin{array}{c}\text { Gene expression fold-change } \\
\text { to parental cell line }\end{array}$} \\
\cline { 2 - 5 } $\begin{array}{l}\text { Drug resistant } \\
\quad \text { variant }\end{array}$ & GSTP1 & GSTA1 & GSTM1 & MGST \\
\hline U-2OS/DX580 & $2.0^{*}$ & 1.1 & 1.0 & $2.2^{*}$ \\
U-2OS/MTX300 & $2.8^{*}$ & 1.2 & 1.1 & $7.0^{*}$ \\
U-2OS/CDDP4 $\mu \mathrm{g}$ & $2.9 *$ & 0.9 & 0.9 & $5.2^{*}$ \\
Saos-2/DX580 & 0.9 & 0.8 & 0.8 & 0.5 \\
Saos-2/MTX300 & $2.2^{*}$ & 1.1 & 0.9 & $3.9^{*}$ \\
Saos-2/CDDP6 $\mu \mathrm{g}$ & $0.3^{*}$ & $114.1^{*}$ & 0.9 & $15.1^{*}$ \\
\hline
\end{tabular}

Data shown in this Table refer to the ratio between the gene expression level of each drug resistant variant and that of its parental cell line. *significantly different from parental cell line $(P<0.01$ by $t$-Student test). assessment (Fig. 2A). GST $\mu$ protein was expressed at very low levels in all cell lines, without any significant change in drug resistant variants (Fig. 2A). GST $\alpha$ protein was undetectable in all cell lines, with the only exception of Saos-2/CDDP6 $\mu$ g which presented a very high amount of protein in agreement with the high GSTAl gene expression level (data not shown).

MGST gene expression was significantly increased in all osteosarcoma drug resistant variants, excepting for Saos-2/DX580 (Table 1). On the basis of these results, the clinical impact of $M G S T$ gene expression was analysed on the same series of 34 clinical samples from patients with primary, non-metastatic osteosarcoma, which had been considered for GSTP1 in our

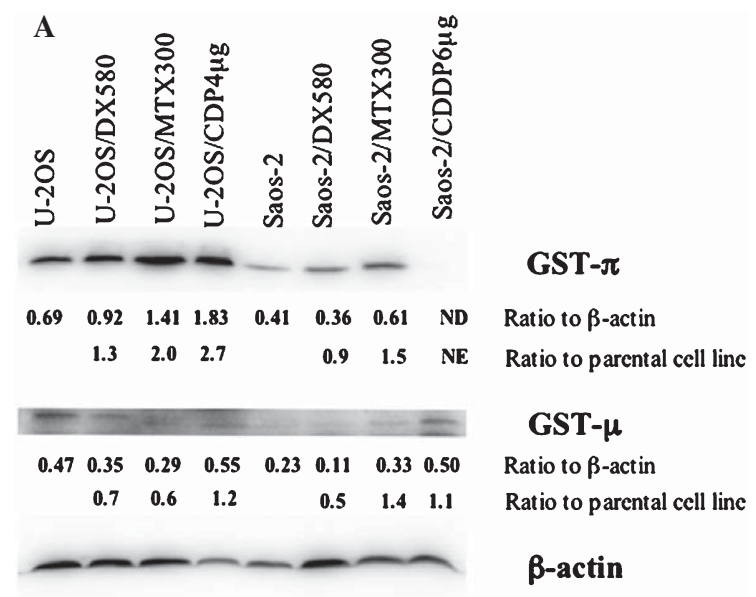

B
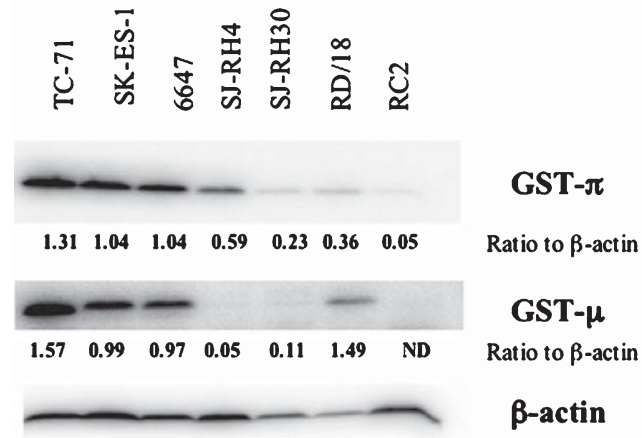

Fig. 2. Intracellular levels of glutathione-S transferase (GST) proteins in the panel of osteosarcoma (panel A), Ewing's sarcoma and rhabdomyosarcoma cell lines (panel B), assessed by western blot. The amount of GST proteins of each cell line was determined by densitometric analysis and normalised to that of $\beta$-actin. For drug resistant variants, each normalised GST protein level was related to that of the corresponding parental cell line. Figure shows data of one representative experiment. ND, not detectable; NE, not evaluable. 


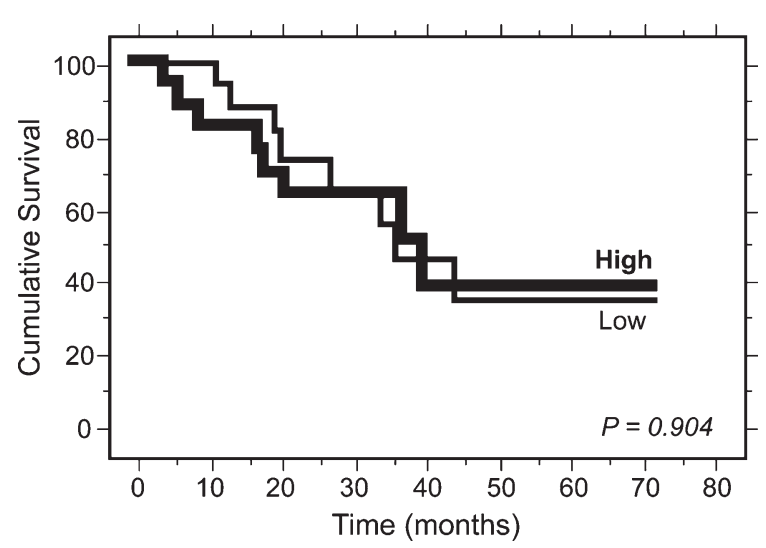

Fig. 3. Event-free survival curves in 34 high-grade osteosarcoma patients, stratified according to the MGST gene expression level at diagnosis. A pooled cDNA from human normal osteoblasts was used as calibrator and patients were stratified into high- or low- expressors by using the median MGST gene expression value as cut-off. Comparison of survival curves was performed by the log-rank test.

previous study [8]. No relationship was found between MGST gene expression level and clinicopathologic parameters (gender, age, histologic subtype, type of surgery, surgical margins, tumour necrosis after preoperative chemotherapy), relapse rate and event-free or overall survival (Fig. 3).

Ewing's sarcoma cell lines showed a variable but relevant expression of GSTP1 and MGST genes (Fig. 1), in agreement with recently reported findings [12]. On the contrary, expression of GSTM1 and GSTA1 was very low and almost undetectable, with the exception of TC-71 cell line which showed an expression level of GSTM1 gene comparable with that of human normal CD34-positive cells (the most appropriate normal reference for these tumour cells). Western blot analyses fully confirmed gene expression results, revealing an evident expression of both GST $\pi$ and GST $\mu$ proteins, which were higher in TC-71 compared to SK-ES-1 and 6647 cell lines (Fig. 2B) in agreement with the gene expression data. Like in osteosarcoma, GST $\alpha$ protein was undetectable in all cell lines (data not shown).

Rhabdomyosarcoma cell lines showed GSTP1 gene expression levels comparable to those found in U2OS and Saos-2 osteosarcoma cell lines and similar or slightly higher to those of normal muscle cells (Fig. 1). Expression of the other three GST genes was, in general, very low, with the exception of MGST gene that was expressed at higher levels in RD/18 and SJ-RH30 cell lines compared to normal muscle cells. Like in osteosarcoma and Ewing's sarcoma, data obtained at gene expression level correlated very well with those derived from western blot analyses (Fig. 2B). Like in osteosarcoma and in Ewing's sarcoma, GST $\alpha$ protein was undetectable in all cell lines (data not shown).

\subsection{In vitro sensitivity to $N B D H E X$}

The in vitro sensitivity to NBDHEX was quantified by evaluating the IC50 value of each cell line (Fig. 4). In general, all cell lines proved to be rather sensitive to NBDHEX, showing IC50 values in the low micromolar- or submicromolar range (from 0.35- to $3.88 \mu \mathrm{mol} / \mathrm{L}$ ), also in presence of higher contents of one or more GST isoenzymes.

In agreement with our recently reported data [8], osteosarcoma U-2OS and Saos-2 parental cell lines confirmed to be highly sensitive to NBDHEX. A decrease of NBDHEX sensitivity compared to parental cell lines was confirmed in U-2OS/DX580 and CDDPresistant variants, which anyway showed IC50 values in the low micromolar range $(2.58 \mu \mathrm{mol} / \mathrm{L}$ for Saos2/CDDP6 $\mu \mathrm{g}, 3.16 \mu \mathrm{mol} / \mathrm{L}$ for U-2OS/DX580 and $3.88 \mu \mathrm{mol} / \mathrm{L}$ for U-2OS/CDDP4 $\mu \mathrm{g}$ ).

Ewing's sarcoma cell lines showed NBDHEX IC50 values ranging from 0.7 - to $2.0 \mu \mathrm{mol} / \mathrm{L}$ (comparable to those observed in the U-2OS and Saos-2 cell lines), confirming their previously reported sentivities to this drug [12].

Rhabdomyosarcoma cell lines showed variable sensitivities to NBDHEX. RD/18 and SJ-RH30 presented, respectively, 0.6- and $1.50 \mu \mathrm{mol} / \mathrm{L}$ IC50 values, which were comparable to those observed in the U-2OS, Saos-2 and Ewing's sarcoma cell lines. On the other hand, RC2 and SJ-RH4 IC50 values (respectively, 3.0and $4.6 \mu \mathrm{mol} / \mathrm{L}$ ) were comparable to those observed in the osteosarcoma drug-resistant variants with the lowest sensitivities to NBDHEX.

\subsection{Cell cycle analysis}

The assessment of the in vitro efficacy of NBDHEX was coupled with cell cycle analyses on the whole cell lines panel (Supplementary Figs. 1-3). In general, NBDHEX induced both a partial blockage of cells in $\mathrm{G} 2 / \mathrm{M}$ phase in the majority of cell lines. However, not all cell lines showed the same response to NBDHEX in terms of cell cycle perturbations. 


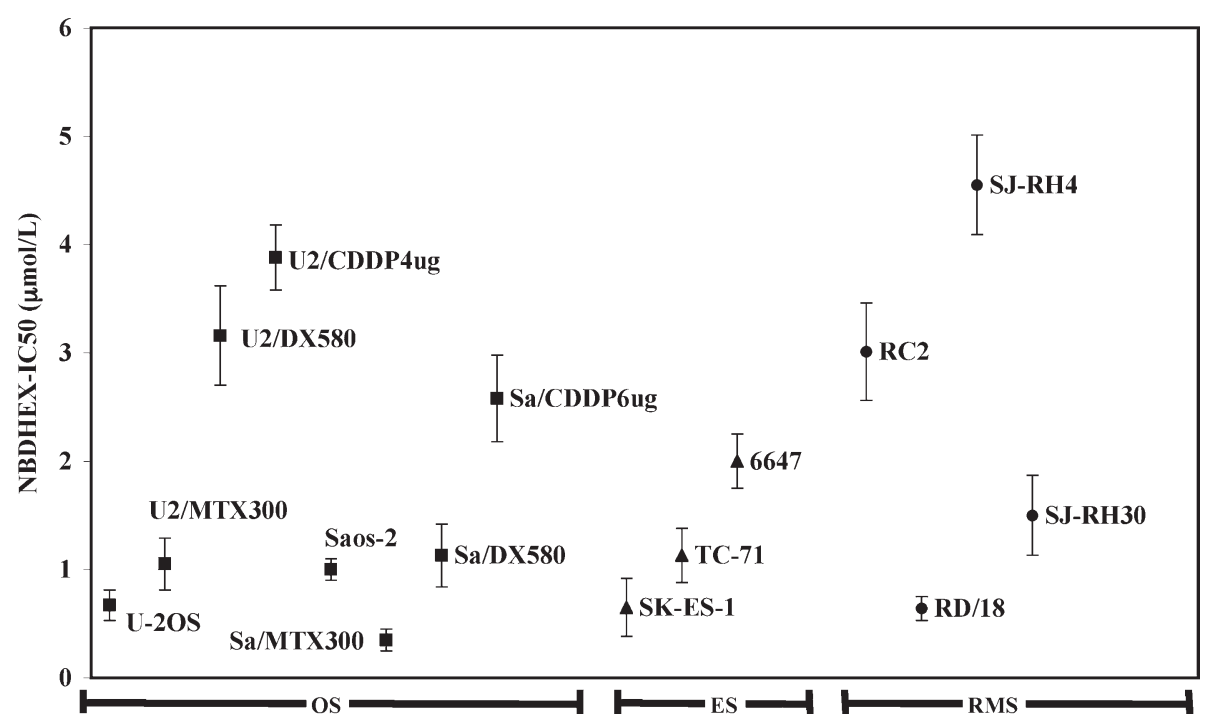

Fig. 4. In vitro sensitivity to NBDHEX of the human osteosarcoma, Ewing's sarcoma and rhabdomyosarcoma cell lines. The graph shows IC50 values (drug concentration resulting in 50\% inhibition of cell growth) after treatment with NBDHEX for 96 hours (osteosarcoma cell lines) or 72 hours (Ewing's sarcoma and rhabdomyosarcoma cell lines). Data are shown as mean value \pm standard deviation of three different experiments. OS, osteosarcoma; ES, Ewing's sarcoma; RMS, rhabdomyosarcoma.

All the U-2OS osteosarcoma cell lines (Supplementary Fig. 1) showed an accumulation of cells in the G2/M phase, with a parallel decrease of cells in G0/G1 phase after treatment with NBDHEX. This effect was more evident at the IC75 dosage. In the U2OS/MTX300 cell line, a remarkable reduction of the $S$ phase at the IC75 dosage was also detected, suggesting that, in this cell line, NBDHEX may also induce a partial cell proliferation blockage.

A prominent accumulation of cells in the G2/M phase, with a parallel decrease of the G0/G1 phase, was also revealed in the Saos-2 and Saos-2/MTX300 cell lines, whereas in Saos-2/DX580 and Saos-2/CDDP6ug variants no remarkable effects of NBDHEX on cell cycle were detected (Supplementary Fig. 1).

Differently from osteosarcoma, in Ewing's sarcoma cell lines no remarkable effects of NBDHEX on cell cycle were detected (Supplementary Fig. 2). Ewing's sarcoma cell lines presented a retardation of the whole cell cycle, producing a slower in vitro growth, rather than a G2/M accumulation as a consequence of NBDHEX treatment.

Among rhabdomyosarcoma cell lines (Supplementary Fig. 3), NBDHEX induced an accumulation of cells in the G2/M phase with a parallel decrease in the percentage of cells in G0/G1 phase only in RC2 and SJ-RH4 cell lines.

\subsection{Apoptosis assay}

The effects of NBDHEX on apoptosis were evaluated after treatment with the IC50 and IC75 drug dosages of each cell lines. Under these experimental conditions, absence or very limited induction of cell death (apoptosis or cell necrosis) was observed in all cell lines (data not shown).

\subsection{NBDHEX interactions with conventional drugs}

Drug-drug interactions analyses considered the combination of NBDHEX with the conventional drugs that are most commonly used in osteosarcoma, Ewing's sarcoma and rhabdomyosarcoma chemotherapy (Table 2).

In osteosarcoma cell lines, association of NBDHEX with DX produced synergistic effects in both U-2OS and Saos-2 parental cell lines and in Saos2/DX580 variant, but showed antagonistic interaction in U-2OS/DX580. When NBDHEX was associated with MTX, the resulting interaction was antagonistic in both parental cell lines and MTX-resistant variants. The effectiveness of NBDHEX in association with CDDP was already analysed and resulted to be 
Table 2

Effects of the in vitro simultaneous administration of NBDHEX and doxorubicin (DX), methotrexate (MTX), or vincristine (VCR) in human osteosarcoma, Ewing's sarcoma and rhabdomyosarcoma cell lines

\begin{tabular}{|c|c|c|c|}
\hline $\begin{array}{l}\text { Cell } \\
\text { line }\end{array}$ & $\begin{array}{c}\text { NBDHEX+ } \\
\text { DX } \\
\text { (CI) }\end{array}$ & $\begin{array}{c}\text { NBDHEX+ } \\
\text { MTX } \\
(\mathrm{CI})\end{array}$ & $\begin{array}{l}\text { NBDHEX+ } \\
\text { VCR } \\
\text { (CI) }\end{array}$ \\
\hline $\mathrm{U}-2 \mathrm{OS}$ & $\begin{array}{l}\text { SYN } \\
(0.79)\end{array}$ & $\begin{array}{c}\text { ant } \\
(2.21)\end{array}$ & \\
\hline Saos-2 & $\begin{array}{c}\text { SYN } \\
(0.71)\end{array}$ & $\begin{array}{c}\text { ant } \\
(1.69)\end{array}$ & \\
\hline U-2OS/DX580 & $\begin{array}{c}\text { ant } \\
(1.32)\end{array}$ & & \\
\hline Saos-2/DX580 & $\begin{array}{l}\text { SYN } \\
(0.71)\end{array}$ & & \\
\hline U-2OS/MTX300 & & $\begin{array}{c}\text { ant } \\
(1.12)\end{array}$ & \\
\hline Saos-2/MTX300 & & $\begin{array}{c}\text { ant } \\
(2.27)\end{array}$ & \\
\hline TC-71 & $\begin{array}{l}\text { ADD } \\
(0.99)\end{array}$ & & $\begin{array}{l}\text { SYN } \\
(0.74)\end{array}$ \\
\hline SK-ES-1 & $\begin{array}{l}\text { ADD } \\
(1.10)\end{array}$ & & $\begin{array}{l}\text { SYN } \\
(0.50)\end{array}$ \\
\hline 6647 & $\begin{array}{l}\text { ADD } \\
(0.94)\end{array}$ & & $\begin{array}{l}\text { SYN } \\
(0.67)\end{array}$ \\
\hline $\mathrm{RC} 2$ & $\begin{array}{c}\text { ant } \\
(1.73)\end{array}$ & & $\begin{array}{c}\text { ant } \\
(1.16)\end{array}$ \\
\hline $\mathrm{RD} / 18$ & $\begin{array}{c}\text { ant } \\
(2.32)\end{array}$ & & $\begin{array}{l}\text { SYN } \\
(0.59)\end{array}$ \\
\hline SJ-RH4 & $\begin{array}{c}\text { ant } \\
(2.33)\end{array}$ & & $\begin{array}{l}\text { ADD } \\
(1.02)\end{array}$ \\
\hline SJ-RH30 & $\begin{array}{c}\text { ant } \\
(3.30)\end{array}$ & & $\begin{array}{c}\text { ant } \\
(1.49)\end{array}$ \\
\hline
\end{tabular}

Abbreviations: CI, combination index; ADD, additive $(0.90 \leq \mathrm{CI}$ $\leq 1.10)$; SYN, synergistic $(\mathrm{CI}<0.90)$; ant, antagonistic $(\mathrm{CI}>1.10)$

invariably additive or synergistic in both parental and CDDP-resistant cell lines [8].

In Ewing's sarcoma cell lines, the combination of NBDHEX with DX proved to be invariably additive, in agreement with the previously reported observation [12]. The effectiveness of association with VCR proved to be synergistic in all cell lines.

In rhabdomyosarcoma cell lines, the obtained results showed that NBDHEX cannot be administrated together with DX or VCR, since these two-drugs combinations proved to be mostly antagonistic.

In order to verify whether a different treatment schedule could overcome the negative interactions of NBDHEX with conventional drugs observed in osteosarcoma and rhabdomyosarcoma cell lines, evaluation of the efficacy of sequential two-drugs exposure were also performed (Table 3 ).
In osteosarcoma cell lines, the sequential exposure of NBDHEX with DX did not succeed in overcoming the antagonistic interaction observed in the U-2OS/DX580 variant. Meanwhile in the other cell lines this combination proved to produce the same synergistic effects obtained with the drug association schedule. Sequential treatment of NBDHEX and MTX did not significantly improve the results obtained in drug association experiments, mainly resulting in antagonsitic interactions. The effectiveness of sequential treatments with NBDHEX and CDDP were already reported to be either additive or synergistic in both parental and CDDP-resistant cell lines [8].

In rhabdomyosarcoma cell lines, the sequential exposure of NBDHEX with DX proved to overcome the negative interactions observed with the association treatments, mostly resulting in synergistic interactions. The same improvement was observed for the sequential treatment of NBDHEX and VCR.

In summary, these findings showed that NBDHEX can be used in association with conventional chemotherapeutics (DX and VCR) in Ewing's sarcoma, whereas sequential treatment schedules have to be considered in osteosarcoma (with DX) and rhabdomyosarcoma (with DX or VCR). On the other hand, NBDHEX cannot be combined with MTX in osteosarcoma cells, neither in association nor in sequential exposure treatment schedules.

\subsection{In vivo efficacy of NBDHEX}

In vivo efficacy of NBDHEX was assessed on TC71 Ewing's sarcoma and on U-2OS osteosarcoma cells to evaluate its activity, respectively, on local tumour growth and metastatic dissemination. Treatments of NBDHEX on TC-71 Ewing's sarcoma cells resulted in a slight inhibition of in vivo tumour cell growth, comparable with that obtained by VCR (Fig. 5). The association of NBDHEX with VCR produced a trend toward a positive combined effect resulting in a further retardation of tumour cell growth. When considered together with the in vitro results, these findings support the cell cycle retardation and cytostatic effects showed by NBDHEX on most cell lines and confirmed the positive interaction of NBDHEX and VCR in Ewing's sarcoma cells.

NBDHEX appeared to be also active in reducing the metastastic ability of U-2OS osteosarcoma cells. In fact, NBDHEX-treated mice showed reduced inci- 
Table 3

Effects of the in vitro sequential administration of NBDHEX and doxorubicin (DX), methotrexate (MTX), cisplatin (CDDP) or vincristine (VCR) in human osteosarcoma and rhabdomyosarcoma cell lines

\begin{tabular}{|c|c|c|c|c|c|c|}
\hline Cell line & $\begin{array}{c}\text { NBDHEX } \\
\downarrow \\
\text { DX } \\
\text { (CI) }\end{array}$ & $\begin{array}{c}\text { DX } \\
\downarrow \\
\text { NBDHEX } \\
\text { (CI) }\end{array}$ & $\begin{array}{c}\text { NBDHEX } \\
\downarrow \\
\text { MTX } \\
\text { (CI) }\end{array}$ & $\begin{array}{c}\text { MTX } \\
\downarrow \\
\text { NBDHEX } \\
\text { (CI) }\end{array}$ & $\begin{array}{c}\text { NBDHEX } \\
\downarrow \\
\text { VCR } \\
\text { (CI) }\end{array}$ & $\begin{array}{c}\text { VCR } \\
\downarrow \\
\text { NBDHEX } \\
\text { (CI) }\end{array}$ \\
\hline U-2OS & $\begin{array}{l}\text { SYN } \\
(0.57)\end{array}$ & $\begin{array}{l}\text { SYN } \\
(0.53)\end{array}$ & $\begin{array}{l}\text { ant } \\
(2.11)\end{array}$ & $\begin{array}{c}\text { ant } \\
(1.54)\end{array}$ & & \\
\hline Saos-2 & $\begin{array}{l}\text { SYN } \\
(0.65)\end{array}$ & $\begin{array}{c}\text { SYN } \\
(0.58)\end{array}$ & $\begin{array}{c}\text { SYN } \\
(0.51)\end{array}$ & $\begin{array}{c}\text { ant } \\
(2.07)\end{array}$ & & \\
\hline U-2OS/DX580 & $\begin{array}{c}\text { ant } \\
(2.34)\end{array}$ & $\begin{array}{c}\text { ant } \\
(2.84)\end{array}$ & & & & \\
\hline Saos-2/DX580 & $\begin{array}{l}\text { SYN } \\
(0.31)\end{array}$ & $\begin{array}{l}\text { SYN } \\
(0.57)\end{array}$ & & & & \\
\hline U-2OS /MTX300 & & & $\begin{array}{l}\text { SYN } \\
(0.83)\end{array}$ & $\begin{array}{c}\text { ant } \\
(3.58)\end{array}$ & & \\
\hline Saos-2/MTX300 & & & $\begin{array}{c}\text { ant } \\
(3.11)\end{array}$ & $\begin{array}{l}\text { ADD } \\
(1.02)\end{array}$ & & \\
\hline $\mathrm{RC} 2$ & $\begin{array}{c}\text { SYN } \\
(0.13)\end{array}$ & $\begin{array}{c}\text { SYN } \\
(0.16)\end{array}$ & & & $\begin{array}{c}\text { SYN } \\
(0.38)\end{array}$ & $\begin{array}{c}\text { SYN } \\
(0.44)\end{array}$ \\
\hline $\mathrm{RD} / 18$ & $\begin{array}{c}\text { ant } \\
(2.79)\end{array}$ & $\begin{array}{c}\text { SYN } \\
(0.37)\end{array}$ & & & $\begin{array}{c}\text { ant } \\
(1.17)\end{array}$ & $\begin{array}{l}\text { SYN } \\
(0.69)\end{array}$ \\
\hline SJ-RH4 & $\begin{array}{c}\text { SYN } \\
(0.72)\end{array}$ & $\begin{array}{c}\text { SYN } \\
(0.56)\end{array}$ & & & $\begin{array}{l}\text { SYN } \\
(0.35)\end{array}$ & $\begin{array}{l}\text { SYN } \\
(0.14)\end{array}$ \\
\hline SJ-RH30 & $\begin{array}{l}\text { SYN } \\
(0.64)\end{array}$ & $\begin{array}{l}\text { SYN } \\
(0.13)\end{array}$ & & & $\begin{array}{l}\text { SYN } \\
(0.59)\end{array}$ & $\begin{array}{l}\text { SYN } \\
(0.73)\end{array}$ \\
\hline
\end{tabular}

Abbreviations: CI, combination index; ADD, additive $(0.90 \leq \mathrm{CI} \leq 1.10)$; $\mathrm{SYN}$, synergistic $(\mathrm{CI}<0.90)$; ant, antagonistic $(\mathrm{CI}>1.10)$.

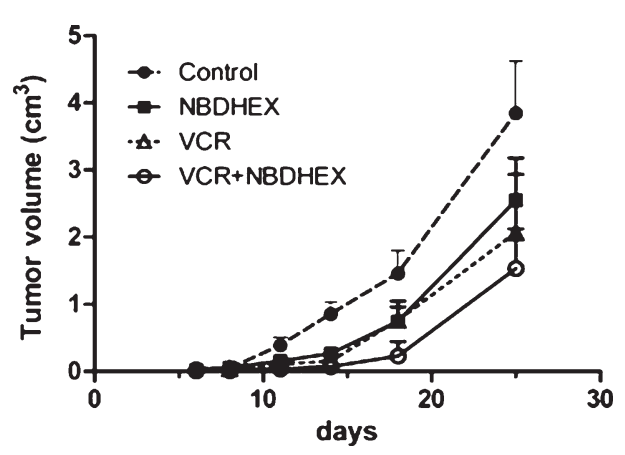

Fig. 5. Inhibition of TC-71 tumour growth in nude mice by NBDHEX treatment with or without vincristine (VCR). Mice were treated per os starting from day 6 daily for five times weekly with NBDHEX $(40 \mathrm{mg} / \mathrm{kg}$ ) or with vehicle alone (controls). In combined treatments, vincristine $(1 \mathrm{mg} / \mathrm{kg} / \mathrm{d}$ i. p.) was added on days 6 and 7 . Points, tumour size mean; bars, SE.

dence and number of lung metastases compared to untreated controls (Table 4).

In all the in vivo experiments, NBDHEX did not show collateral toxicity and proved to be very well tolerated.
Table 4

Metastatic ability in nude female mice intraveneously (i.v.) pretreated with anti asialo GM1 antiserum 24 hours prior to the i.v. injection of $2 \times 10^{6} \mathrm{U}-2 \mathrm{OS}$ human osteosarcoma cells

\begin{tabular}{lcc}
\hline Group & $\begin{array}{c}\text { Incidence of lung metastases } \\
\text { (positive mice/total) }\end{array}$ & $\begin{array}{c}\text { Total number of } \\
\text { metastases }\end{array}$ \\
\hline Control & $5 / 9$ & 29 \\
NBDHEX-treated & $3 / 10$ & 3 \\
\hline
\end{tabular}

\section{Discussion}

Glutathione-S-tranferases (GSTs) are members of a multi-gene family of proteins involved in cellular detoxification processes. Several studies have demonstrated that the expression of some GSTs (in particular GSTPi) is elevated in many untreated human tumours in comparison with their matched normal tissue and that increased levels of various GSTs may occur in response to antitumour drug selection pressure in vitro $[10,13]$. Furthermore, cumulative evidence has suggested that overexpression of GSTs may play a 
role in resistance to cancer chemotherapeutics in different neoplasms $[10,11]$, including musculoskeletal tumours $[8,12,13]$. These findings indicate that GSTs represent promising targets for cancer therapy, in order to achieve higher and, hopefully, more selective efficacy of anticancer treatments, as well as to overcome drug resistance.

In principle, targeting of GSTs can be accomplished through different approaches, one of which is the use of GSTs inhibitors in order to increase the efficacy of conventional anticancer agents. Recently, a family of 7-nitro-2,1,3-benzoxadiazole (NBD) derivatives has been designed and synthesized at the University of Tor Vergata (Rome, Italy) [3, 9, 17]. These agents have shown remarkable cytotoxicity in various cancer cell lines (IC50 values in the low micromolar/submicromolar range) and a strong inhibitory activity towards different human GSTs (mainly GSTP1-1, GSTM2-2 and GSTA1-1) [3, 9, 17]. Among these derivatives, the 6-(7-nitro-2,1,3benzoxadiazol-4-ylthio)hexanol (NBDHEX) emerged as the most potent one [9] and showed to be active also in drug resistant cells [8, 17, 18]. For these reasons, in this study NBDHEX has been considered for more detailed analyses to better evaluate its in vitro and in vivo efficacy on a panel of cell lines from the three most common pediatric muscoloskeletal tumours: osteosarcoma, Ewing's sarcoma and rhabdomyosarcoma.

Since the previously reported data in osteosarcoma [8] and Ewing's sarcoma cells [12] about the status of the four major GST isoenzymes (namely, GSTP1, GSTM1, GSTA1 and MGST) needed to be implemented, the first phase of this study focused on the analysis of these enzymes in our experimental models.

In osteosarcoma, it has been previously demonstrated that GSTP1 level and/or activity increased in all drug resistant variants compared to their corresponding parental cell lines, and that its overexpression was a poor prognostic marker [8]. Findings obtained in this study confirmed that GSTP1 increased expression is associated with the development of drug resistance in 4 out of 6 drug resistant variants. On the contrary, GSTM1 and GSTA1 were expressed at very low levels, being almost undetectable in all cell lines with the only exception of Saos-2/CDDP6 $\mu$ g which presented a very high expression of GSTA1, whose possible impact on CDDP resistance needs to be further defined.

The analysis of MGST showed that also the expression level of this isoenzyme significantly increased in all drug resistant variants excepting for Saos-2/DX580, suggesting its possible involvement in osteosarcoma drug resistance. However, this hypothesis was not supported by the analyses performed on clinical samples, which did not reveal any correlation between MGST expression and treatment response or prognosis.

Similarly to osteosarcoma, Ewing's sarcoma cell lines showed variable but relevant expression of GSTP1 and MGST genes, in agreement with recently reported findings [12]. GSTM1 and GSTA1 expression was very low and almost undetectable in all cell lines (with the only exception of TC-71), further confirming the prevalent importance of GSTP1 and MGST isoenzymes.

GSTP1 and MGST appeared to be the most relevant isoenzymes also in rhabdomyosarcoma cell lines, whereas GSTMI and GSTA1 expression was invariably low.

In summary, the whole body of evidence found in this part of the study demonstrated that osteosarcoma, Ewing's sarcoma and rhabdomyosarcoma cell lines expressed variable amounts of GST isoenzymes, GSTP1 and MGST being the most widely expressed and associated with drug resistance in several osteosarcoma cell lines. Therefore, the second phase of this study focused on the preclinical validation of NBDHEX, a GST-targeting molecule which has shown interesting activity on human osteosarcoma and Ewing's sarcoma cell lines [8, 12].

Analysis of the in vitro activity of NBDHEX showed that this drug was very active in all the cell lines here considered, with IC50 values in the low micromolar/submicromolar range, independently from the status of GST isoenzymes intracellular contents. These findings indicate that NBDHEX activity is not strictly related to the status of GSTP1, which is its major target, and thus that this agent may be considered for treating also cells with alteration of different GST isoenzymes. Moreover, this study further demonstrated that NBDHEX is active also in cell lines with increased GST levels, which are less responsive or even resistant to conventional chemotherapeutic drugs.

Cell cycle and apoptosis analyses indicated that, in our experimental conditions, efficacy of NBDHEX appeared to mainly derive from cytostatic rather than cytotoxic effects, leading to an accumulation in the $\mathrm{G} 2 / \mathrm{M}$ phase in several cell lines, whereas apoptosis induction was always low (less than $10 \%$ of total cells after NBDHEX treatment). This cell cycle perturbation 
was more evident in osteosarcoma and rhabdomyosarcoma cell lines, whereas in Ewing's sarcoma cell lines a retardation of the whole cell cycle, leading to a slower cell growth, rather than a G2/M accumulation was present as a consequence of NBDHEX treatment. It has, however, to be taken into account that GSTs interact with several critical kinases involved in apoptosis and cell proliferation, and that interfering with these networks may produce different effects depending on the cellular background (including the possibility that cells are driven to senescence). Other ongoing studies have been disclosing novel details of NBDHEX mechanisms of action which may clarify the biologic bases of its effectiveness and increase its therapeutic window (Sau et al., submitted).

In view of a possible future clinical use of this agent, information on the interaction of NBDHEX with conventional drugs had to be further explored in order to evaluate whether it may improve the patients cure probability by enhancing the efficacy of conventional chemotherapeutics. Our previous analyses already showed that NBDHEX positively interact and enhance the activity of CDDP in osteosarcoma and of DX in Ewing's sarcoma cell lines [8, 12]. In this study, we performed additional drug-drug interaction analyses, in which NBDHEX was administered in association or sequentially to the other drugs that are most commonly used in conventional chemotherapy regimens (DX and MTX for osteosarcoma; VCR for Ewing's sarcoma; DX and VCR for rhabdomyosarcoma). This additional evaluation showed that NBDHEX can be combined with DX also in osteosarcoma and with VCR in Ewing's sarcoma, as well as used in sequential treatment schedules with DX and VCR in rhabdomyosarcoma, further supporting its potential clinical use. On the other side, our findings clearly showed that NBDHEX cannot be used in association with MTX, since the interaction with this drug was almost invariably antagonistic, most probably because of the NBDHEX-induced cell cycle retardation which severely limits the MTX efficacy. The antagonistic interaction which was observed between NBDHEX and DX the U-2OS/DX580 osteosarcoma cell line needs to be further investigated, and it is most probably related to characteristics of this cell line which are not strictly connected to the GSTs status.

In vivo experiments fully confirmed the in vitro evidence of a cytotastic rather than cytotoxic actions of NBDHEX, as well as its positive interaction with VCR.
In fact, NBDHEX was able to slow down but not abolish the in vivo growth of TC-71 in Ewing's sarcoma cells and positively interacted with VCR, in agreement with the in vitro results. Of interest was also the finding that NBDHEX may reduce the metastatic potential of $\mathrm{U}-2 \mathrm{OS}$ osteosarcoma cells, indicating that this agent may also interfere with tumour cell biological aggressiveness.

In summary, the whole body of evidence found in this study indicated that targeting GSTs in osteosarcoma, Ewing's sarcoma and rhabdomyosarcoma may be an interesting new therapeutic option, which can be considered for patients who are scarcely responsive to conventional regimens. NBDHEX appeared to be a very promising candidate to target and inhibit GSTs, also because it appeared to be able to overcome drug resistance mechanisms against some conventional chemotherapeutics. However, the treatment schedule involving the combined use of NBDHEX with conventional drugs must be carefully designed by taking into consideration these preclinical indications. Our findings, together with the availability of new NBDHEX analogouses with higher solubility in phisiologic conditions which have been already developed and are presently under pre-clinical validation, may further facilitate the inclusion of these new agent(s) in phase I-II clinical protocols.

\section{Acknowledgments}

The authors sincerely thank Dr. Giovanna Magagnoli for tissue banking and Dr. Cristina Ferrari for follow-up data updating.

This study was supported by grants from: Istituto Ortopedico Rizzoli (Ricerca Corrente); Associazione Italiana per la Ricerca sul Cancro (A. I. R. C.); Italian Ministry of Health (ACC, Alleanza Contro il Cancro Project); EuroBoNeT, an European Commission-granted Network of Excellence for studying the pathology and genetics of bone tumours (LSHC-CT-2006-018814).

\section{Conflict of interest}

Authors disclose no financial and personal relationships with other people or organisations that could have inappropriately influenced or biased their work. 


\section{Supplementary material}
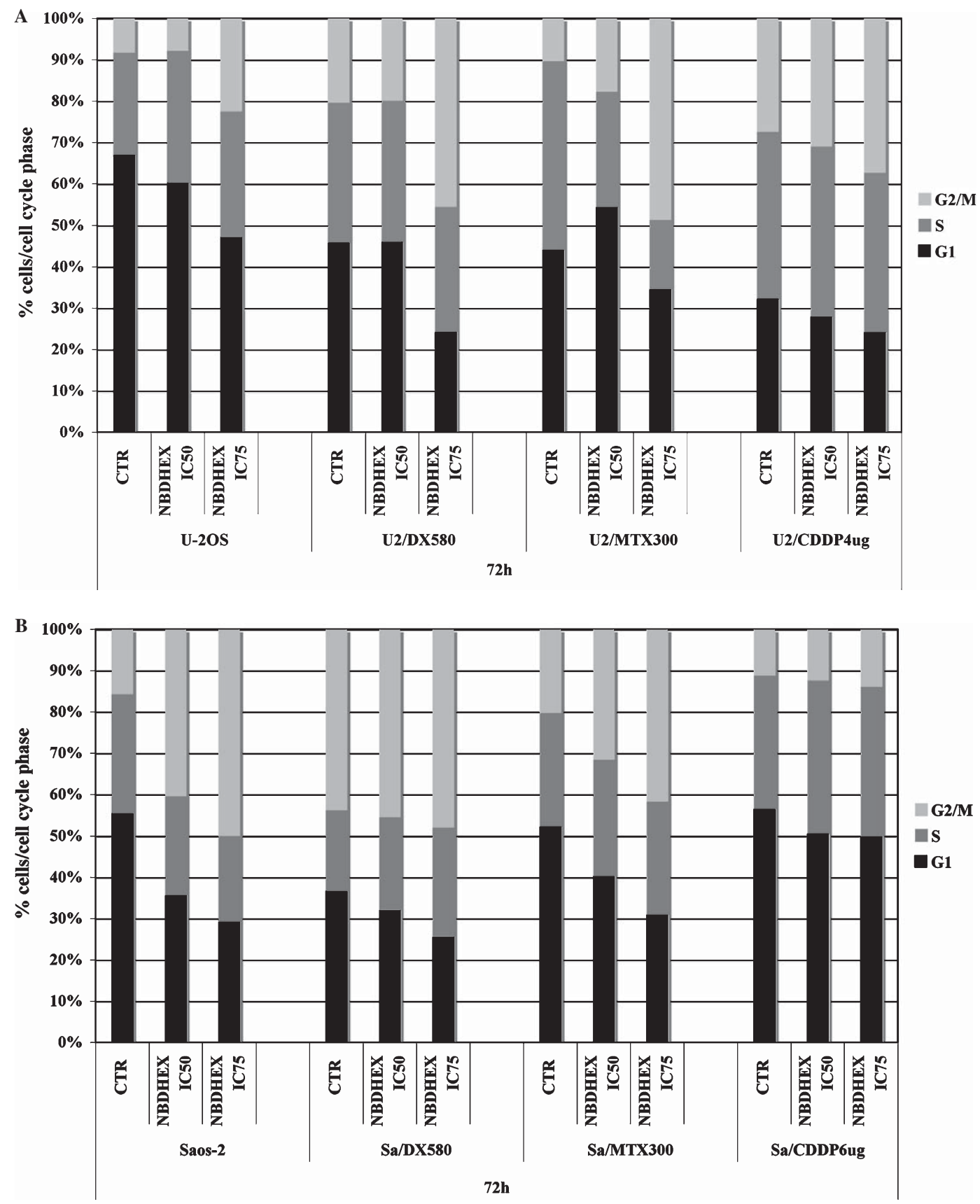

Supplementary Figure 1. Cell cycle phase perturbations induced by treatment for 72 hours with equitoxic doses of NBDHEX (corresponding to the IC50 or IC75 concentration of each cell line) in U-2OS and Saos-2 human osteosarcoma cell lines and in their drug resistant variants. Data refer to the percentage of cells for each cell cycle phase and are representative of at least two different experiments. 


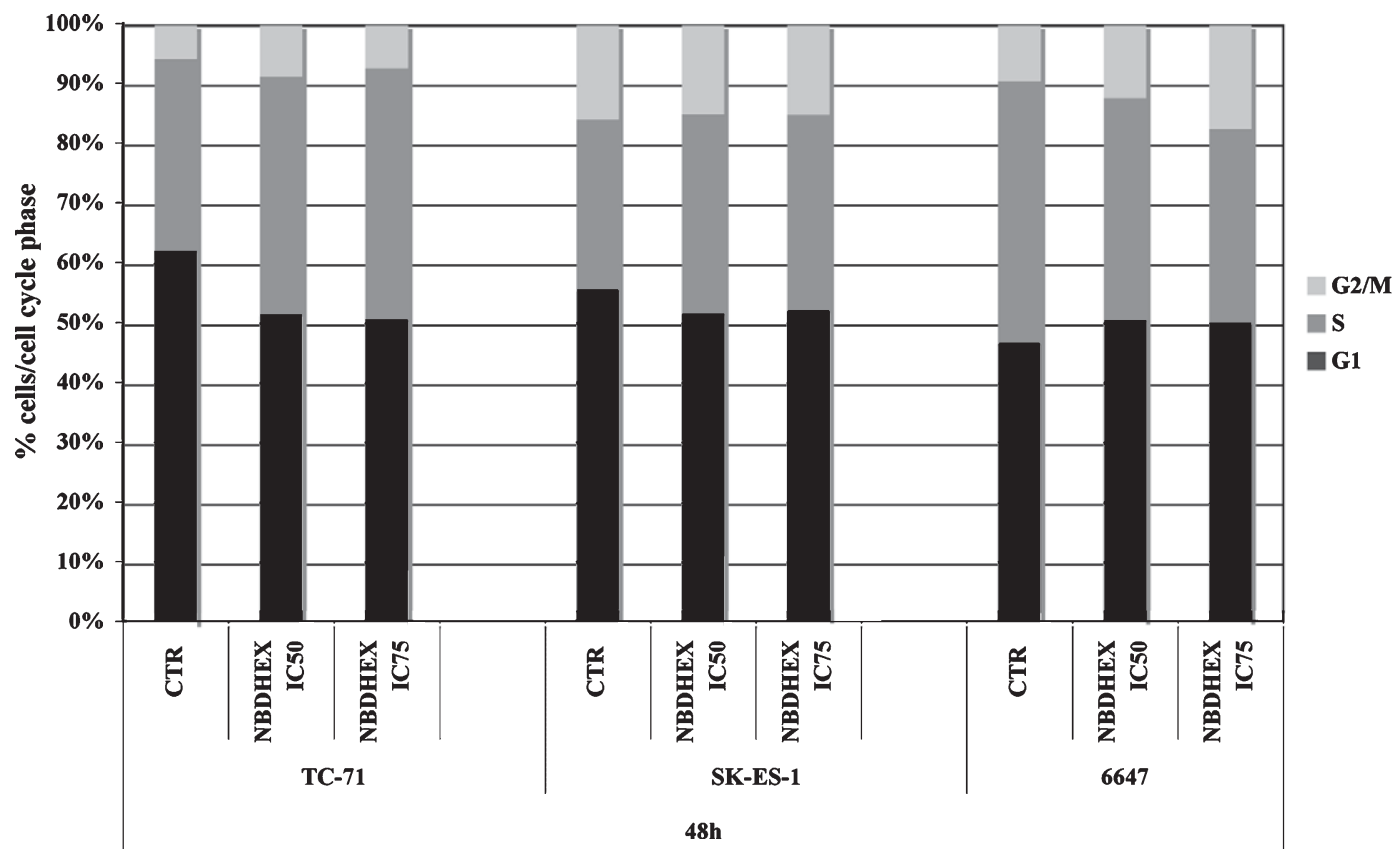

Supplementary Figure 2. Cell cycle phase perturbations induced by treatment for 48 hours with equitoxic doses of NBDHEX (corresponding to the IC50 or IC75 concentration of each cell line) in human Ewing's sarcoma cell lines. Data refer to the percentage of cells for each cell cycle phase and are representative of at least two different experiments.

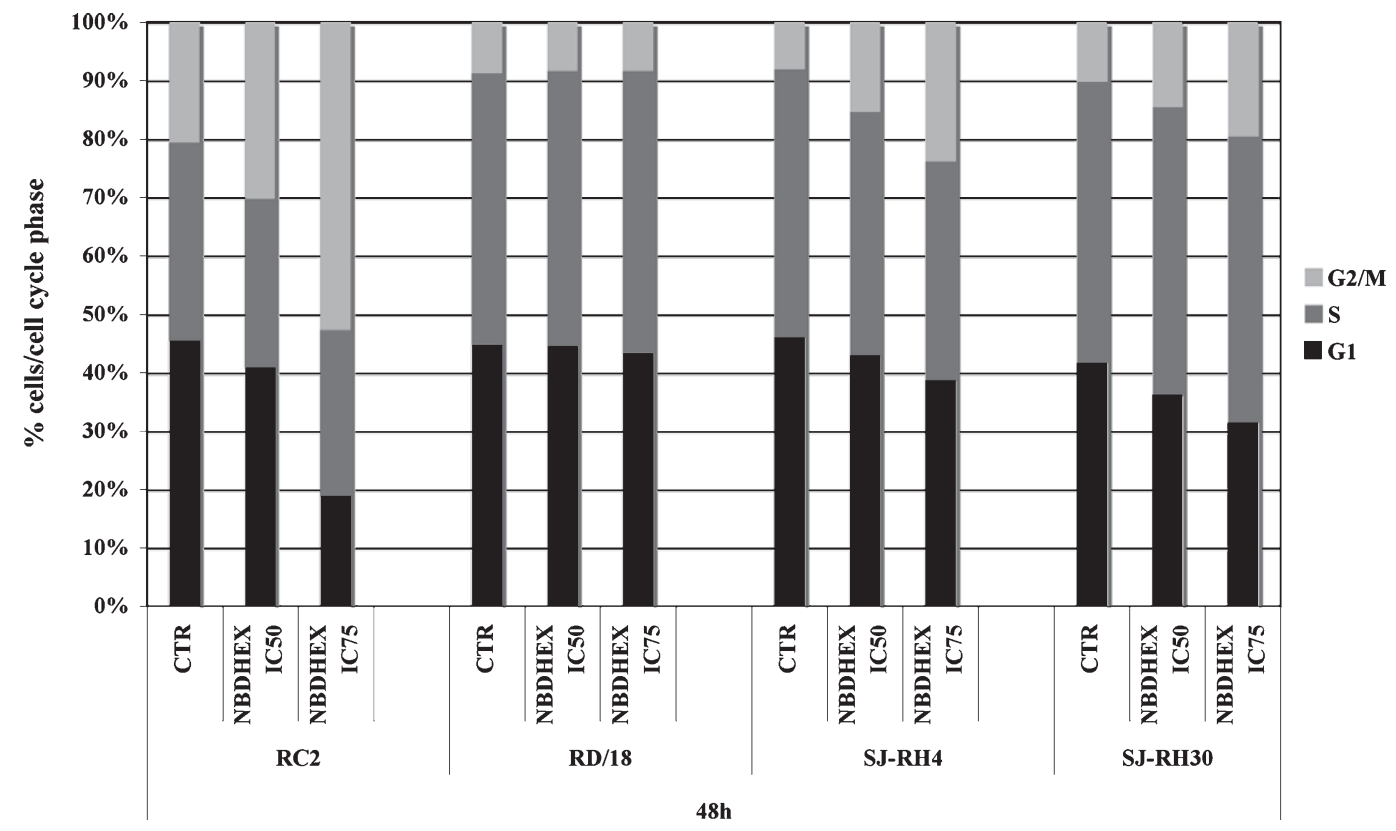

Supplementary Figure 3. Cell cycle phase perturbations induced by treatment for 48 hours with equitoxic doses of NBDHEX (corresponding to the IC50 or IC75 concentration of each cell line) in human rhabdomyosarcoma cell lines. Data refer to the percentage of cells for each cell cycle phase and are representative of at least two different experiments. 


\section{References}

[1] M. Campanacci, Bone Soft Tissue Tumours 2nd ed., SpringerVerlag, Wien, Austria, 1999.

[2] T.C. Chou, R.J. Motzer, Y. Tong and G.J. Bosl, Computerized quantitation of synergism and antagonism of taxol, topotecan, and cisplatin against human teratocarcinoma cell growth: a rational approach to clinical protocol design, $J$ Natl Cancer Inst 86 (1994), 1517-1524.

[3] L. Federici, C. Lo Sterzo, S. Pezzola, A. Di Matteo, F. Scaloni G. Federici and A.M. Caccuri, Structural basis for the binding of the anticancer compound 6-(7-nitro-2,1,3-benzoxadiazol4-ylthio)hexanol to human glutathione s-transferases, Cancer Res 69 (2009), 8025-8034.

[4] C.M. Hattinger, M. Pasello, S. Ferrari, P. Picci and M. Serra, Emerging drugs for high-grade osteosarcoma, Expert Opin Emerg Drugs 15 (2010), 615-634.

[5] Y. Kawano, K. Taniguchi, A. Toshitani and K. Nomoto, Synergistic defense system by cooperative natural effectors against metastasis of B16 melanoma cells in $\mathrm{H}-2$-associated control: different behavior of $\mathrm{H}-2+$ and $\mathrm{H}-2-$ cells in metastatic processes, J Immunol 136 (1986), 4729-4734.

[6] P. Nanni, S. Schiaffino, C. De Giovanni, G. Nicoletti, G. Prodi, B. Del Re, V. Eusebi, C. Ceccarelli, L. Saggin and P.L. Lollini, RMZ: a new cell line from a human alveolar rhabdomyosarcoma. In vitro expression of embryonic myosin, Br J Cancer 54 (1986), 1009-1014.

[7] T. Nomura, N. Tamaoki, A. Takakura and H. Suemizu, Basic concept of development and practical application of animal models for human diseases, Curr Top Microbiol Immunol 324 (2008), 1-24.

[8] M. Pasello, F. Michelacci, I. Scionti, C.M. Hattinger, M. Zuntini, A.M. Caccuri, K. Scotlandi, P. Picci and M. Serra, Overcoming glutathione S-transferase P1-related cisplatin resistance in osteosarcoma, Cancer Res 68 (2008), 6661-6668.

[9] G. Ricci, F. De Maria, G. Antonini, P. Turella, A. Bullo, L. Stella, G. Filomeni, G. Federici and A.M. Caccuri, 7Nitro-2,1,3-benzoxadiazole derivatives, a new class of suicide inhibitors for glutathione S-transferases. Mechanism of action of potential anticancer drugs, J Biol Chem 280 (2005), 26397-26405.

[10] P. Ruzza, A. Rosato, C.R. Rossi, M. Floreani and L. Quintieri, GlutathioneTransferases as Targets for Cancer Therapy, AntiCancer Agents in Medicinal Chemistry 9 (2009), 763-767.
[11] A. Sau, F. Pellizzari Tregno, F. Valentino, G. Federici and A.M. Caccuri, Glutathione transferases and development of new principles to overcome drug resistance, Arch Biochem Biophys 500 (2010), 116-122.

[12] K. Scotlandi, D. Remondini, G. Castellani, M.C. Manara, F. Nardi, L. Cantiani, M. Francesconi, M. Mercuri, A.M. Caccuri, M. Serra, S. Knuutila and P. Picci, Overcoming resistance to conventional drugs in Ewing sarcoma and identification of molecular predictors of outcome, J Clin Oncol 27 (2009), 2209-2216.

[13] G. Seitz, M. Bonin, J. Fuchs, S. Poths, P. Ruck, S.W. Warmann and S. Armeanu-Ebinger, Inhibition of glutathioneS-transferase as a treatment strategy for multidrug resistance in childhood rhabdomyosarcoma, Int J Oncol 36 (2010), 491-500.

[14] M. Serra, K. Scotlandi, M.C. Manara, D. Maurici, P.L. Lollini, C. De Giovanni, G. Toffoli and N. Baldini, Establishment and characterization of multidrug-resistant human osteosarcoma cell lines, Anticancer Res 13 (1993), 323-329.

[15] M. Serra, G. Reverter-Branchat, D. Maurici, S. Benini, J.N. Shen, T. Chano, C.M. Hattinger, M.C. Manara, M. Pasello, K. Scotlandi and P. Picci, Analysis of dihydrofolate reductase and reduced folate carrier gene status in relation to methotrexate resistance in osteosarcoma cells, Ann Oncol 15 (2004), $151-160$.

[16] M.C.G. Stevens, Treatment for childhood rhabdomyosarcoma: the cost of cure, Lancet Oncol 6 (2005), 77-84.

[17] P. Turella, C. Cerella, G. Filomeni, A. Bullo, F. De Maria, L. Ghibelli, M.R. Ciriolo, M. Cianfriglia, M. Mattei, G. Federici, G. Ricci and A.M. Caccuri, Proapoptotic activity of new glutathione S-transferase inhibitors, Cancer Res 65 (2005), 3751-3761.

[18] P. Turella, G. Filomeni, M.L. Dupuis, M.R. Ciriolo, A. Molinari, F. De Maria, M. Tombesi, M. Cianfriglia, G. Federici, G. Ricci and A.M. Caccuri, A strong glutathione Stransferase inhibitor overcomes the P-glycoprotein-mediated resistance in tumour cells. 6-(7-Nitro-2,1,3-benzoxadiazol4-ylthio)hexanol (NBDHEX) triggers a caspase-dependent apoptosis in MDR1-expressing leukemia cells, J Biol Chem 281 (2006), 23725-23732. 


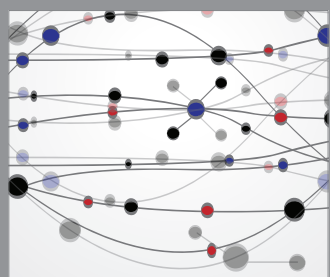

The Scientific World Journal
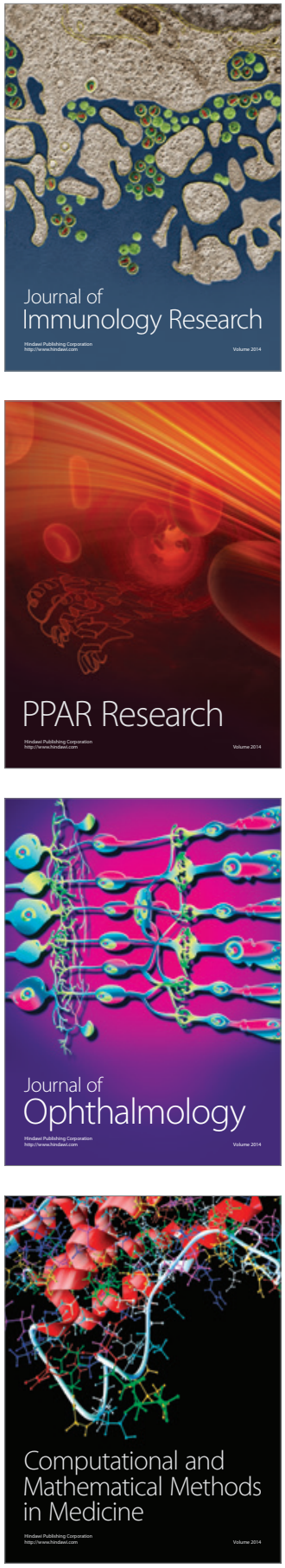

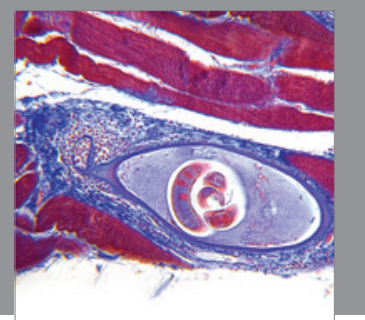

Gastroenterology

Research and Practice
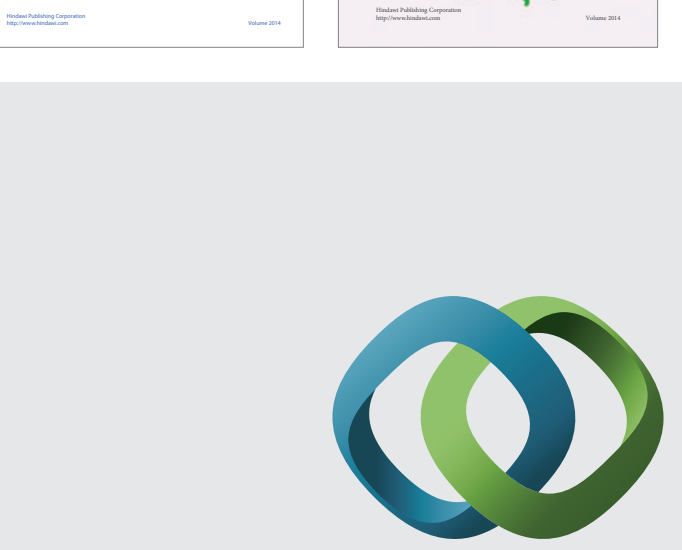

\section{Hindawi}

Submit your manuscripts at

http://www.hindawi.com
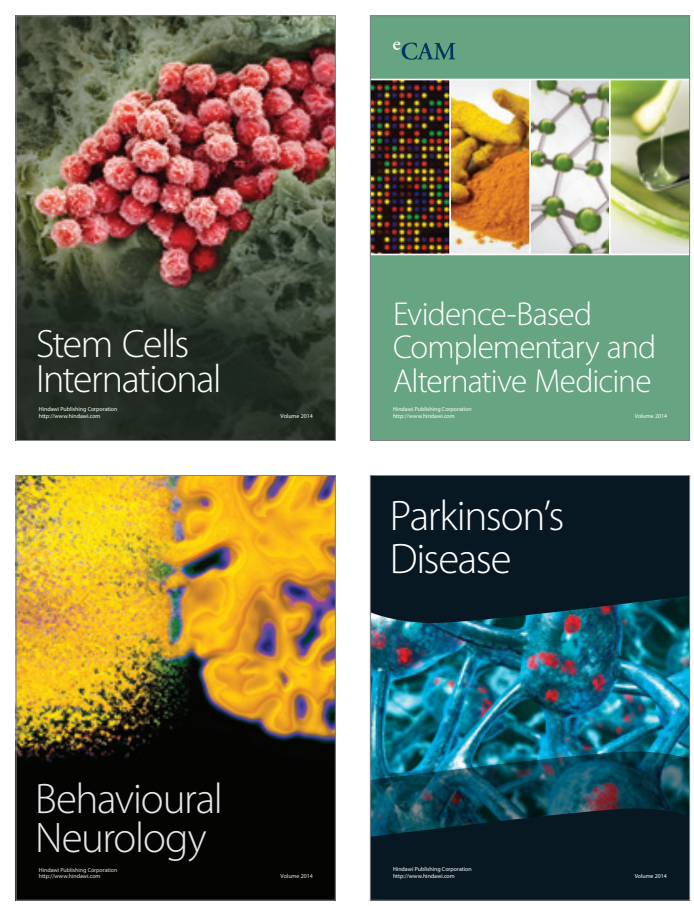

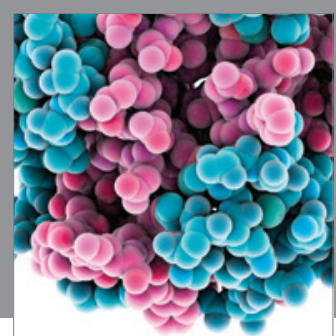

Journal of
Diabetes Research

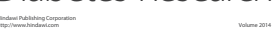

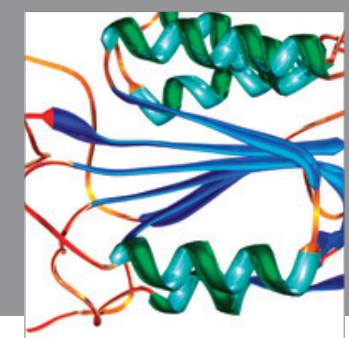

Disease Markers
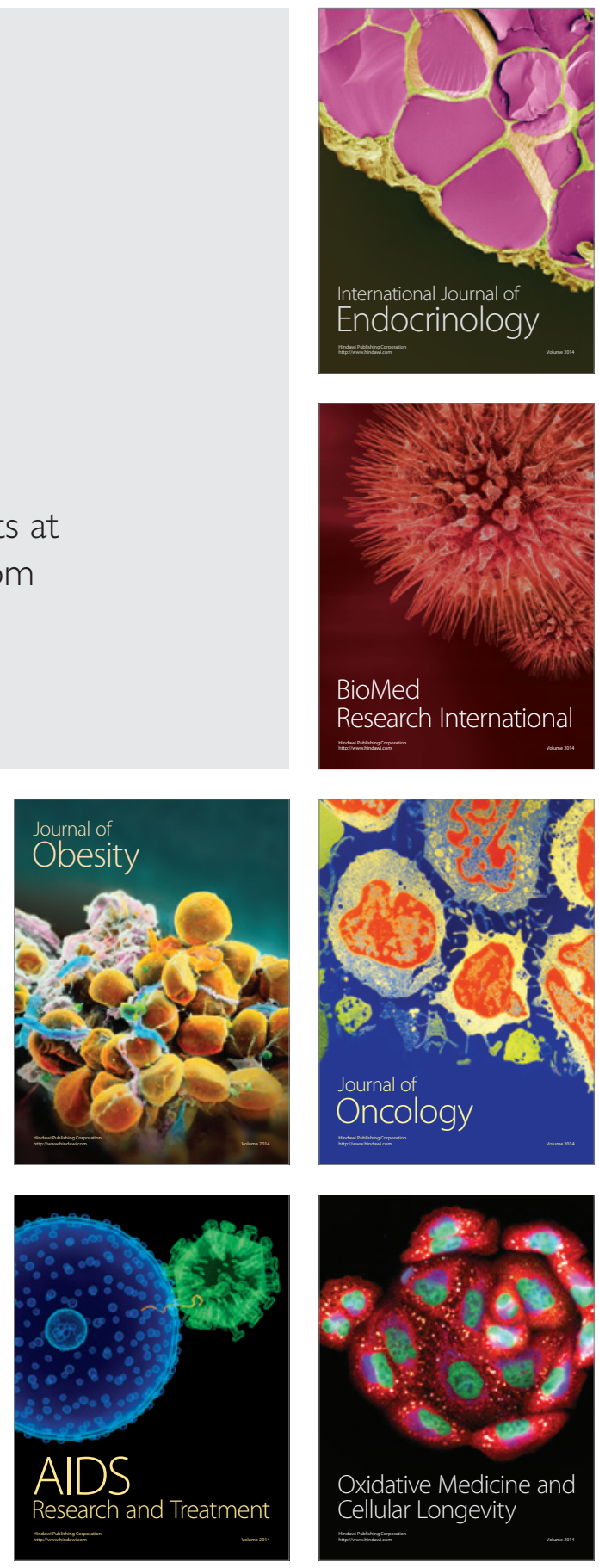